\title{
Does Urban Rail Transit Discourage People from Owning and Using Cars? Evidence from Beijing, China
}

\author{
Shasha Liu $\mathbb{D}^{1},{ }^{1}$ Enjian Yao $\mathbb{D D}^{1},{ }^{1}$ and Toshiyuki Yamamoto $\mathbb{D}^{2}$ \\ ${ }^{1}$ MOE Key Laboratory for Urban Transportation Complex Systems Theory and Technology, Beijing Jiaotong University, Beijing, China \\ ${ }^{2}$ Institute of Materials and Systems for Sustainability, Nagoya University, Nagoya, Japan \\ Correspondence should be addressed to Enjian Yao; enjyao@bjtu.edu.cn
}

Received 2 March 2018; Revised 8 June 2018; Accepted 24 June 2018; Published 6 August 2018

Academic Editor: Gonçalo Homem de Almeida Correia

Copyright (c) 2018 Shasha Liu et al. This is an open access article distributed under the Creative Commons Attribution License, which permits unrestricted use, distribution, and reproduction in any medium, provided the original work is properly cited.

\begin{abstract}
With the rapid urbanization and motorization, many cities are developing urban rail transit (URT) to reduce car dependence. This paper explores the URT effect on car ownership and use based on the home-based work tour data in Beijing, China. Considering the mediating effects of car ownership and travel distance simultaneously, we develop a structural equation model to examine the complex relationship among URT, car ownership, travel distance, and car use. The results indicate that URT plays an important role in reducing car dependence. Living within URT catchment areas by itself is not significantly associated with car ownership and use, but if the workplace is near a URT station, people are less likely to own and use cars. People who both live and work near URT station areas have lower probability of owning and using cars. Moreover, car ownership and travel distance mediate the relationship between URT and car use, and the mediating effect of car ownership is greater than travel distance. Our study verifies that URT does discourage people from owning and using cars, which may have important implications for developing cities to make response to the ongoing motorization.
\end{abstract}

\section{Introduction}

Increasing car travel demand has resulted in numerous problems, such as traffic congestion, environmental pollution, road accidents, and global warming $[1,2]$. In an attempt to get people out of their cars and address the above problems, great importance has been attached to urban rail transit (URT) $[3,4]$. Many cities have invested heavily on URT systems, especially in fast-growing developing countries [5]. In China, more than 30 cities have URT lines in operation, and some cities are planning or constructing URT systems by the end of 2017. In India, metro is operational in 10 cities, under construction in 5 cities, and planned in 17 cities [6]. For these cities that are experiencing fast-paced urbanization, if empirical studies verify the importance of URT in reducing car dependence, this would provide great potential to intervene the development of urbanization [7] and make effective response to the continuing motorization.

Although many studies have examined the influence of URT on car ownership and use, the significance of URT effect varies a lot in different empirical studies. Some studies verify the negative impact of URT proximity on car ownership and use after controlling for other factors [8-12], but other studies show few effects $[13,14]$. Moreover, limited efforts have been made to explore whether living within URT catchment areas influences car ownership and use differently compared with working near a URT station. Besides, most existing studies explore the relationship between URT and different dimensions of travel behavior (e.g., car ownership, mode choice and travel distance) separately [15]. Some consider car ownership and travel distance as the endogenous variables explained by sociodemographics and built environment $[1,16]$, while other studies treat them as the exogenous variables to explain travel mode choice behavior $[4,17]$. To our knowledge, few studies consider the intermediary nature of car ownership and travel distance simultaneously when modeling the URT effect on mode choice behavior.

This paper attempts to address the above limitations. Considering the mediating effects of car ownership and travel distance simultaneously, we utilize structural equation modeling (SEM) to explore the complex relationship among URT, car ownership, travel distance, and car use based on 
home-based work tour data in Beijing, China. We endeavor to answer the following questions. First, does URT play a role in reducing car dependence? Does living near a URT station affect car ownership and use differently than working near a URT station? Second, do car ownership and travel distance medicate the relationship between built environment and travel mode choice? How does URT influence car use through the medicating variables car ownership and travel distance?

The remaining part of this paper is structured as follows. The next section reviews previous work on the URT effect on travel behavior. The third section describes the data, the variables, and the modeling approach. The subsequent section focuses on the empirical results. The fifth section discusses the important findings. The conclusion is then given in the final section.

\section{Literature Review}

Many studies have explored the relationship between built environment and travel behavior [19-23], in an attempt to guide urban planning practice to reduce automobile dependence and related environment and social costs [24]. Built environment is usually measured as 6Ds [25], including density, diversity, design, destination accessibility (e.g., accessibility to jobs, distance to destination), distance to transit, and demand management. These studies shed light on the relationship between transit and travel behavior $[13,16,26$, 27]. With the rapid development of URT, the influence of URT on travel behavior started to attract wide attention [10$12,14]$.

Although some studies have examined the URT effect on travel behavior, they produce mixed results. Some verify that URT plays an important role in reducing car ownership and use after controlling for other factors [10-12, 17]. Zhang et al. [10] and Huang et al. [11] found that households are less likely to own cars if the residential neighborhoods have URT service. Shen et al. [4] proved that people who live or work near a URT station prefer URT rather than car in Shanghai, China. Zegras [16] found that living near URT is associated with low car ownership and short VKT (vehicle kilometers travelled) in Santiago de Chile. However, other studies find few effect of URT on car ownership and use. Cao and Cao [14] found that LRT (light rail transit) does not have an independent effect on car ownership after controlling for neighborhood design and self-selection in the MinneapolisSt. Paul metropolitan area, USA. Shen et al. [4] detected no significant effect of residential URT proximity and workplace URT proximity on car ownership in Shanghai, China. Li and Zhao [1] concluded that residential distance to URT station is not significantly associated with work VKT for private cars. To our knowledge, there is no consensus on the URT effects on car ownership and use.

Apart from the mixed outcomes, previous studies have several limitations. First, most of these studies focus on how residential URT proximity influences travel behavior. Limited efforts have been made to examine differences in travel behavior between people who live near URT station areas versus people who work within URT catchment areas. Shiftan and Barlach [28] found that built environment at the workplace has significant effects on the commute mode choice. Further, some studies concluded that built environment at the workplace plays a more important role than that at the residence in the travel decisions [29-31]. Therefore, it is necessary to take workplace URT proximity as well as residential URT proximity into account when evaluating the URT effect on travel behavior.

Second, many studies use trip-based models [10-12, 14], while people typically decide which mode to use for the entire tour (including the outbound and return trips plus any necessary intermediate stops) before leaving home [32]. So tour-based models match the travel decision-making process more closely. Tour complexity is usually studied by two different approaches: one is a categorical classification and the other focuses on the number of activities or trip legs within a tour [33]. It is found that more stops within a tour are associated with higher probability of using car rather than public transit $[30,33,34]$.

Third, most of these studies examine the relationship between URT and different dimensions of travel behavior (e.g., car ownership, mode choice, and travel distance) separately. Some studies treat car ownership and travel distance as the endogenous variables explained by sociodemographics and built environment $[1,16]$, while other studies consider them as the exogenous variables to explain mode choice behavior [4, 17]. However, Van Acker and Witlox [35] concluded that car ownership mediates the relationship between built environment and travel mode choice. Ignoring the mediating effects of car ownership may result in a misspecification of the built environment effects on car use. Van Acker and Witlox [34] and Ding et al. [15] found that travel distance also mediates the connection between built environment and mode choice decision. Nevertheless, there are very limited studies that consider the intermediary nature of car ownership and travel distance simultaneously [15, 34].

This study attempts to address these limitations and shed light on how residential and workplace URT proximity affect car ownership and use. Considering the intermediary nature of car ownership and travel distance simultaneously, we apply the SEM to explore the complex relationship among URT, car ownership, travel distance, and car use based on home-based work tour data in Beijing, China.

\section{Methodology}

3.1. Study Area. To explore the URT effects on car ownership and use, we undertake an empirical study of Beijing, the capital of China. It is about $16410 \mathrm{~km}^{2}$ and is divided into 16 administrative districts, 6 of which are in the urban area, as presented in Figure 1. Beijing has experienced fast-paced urbanization in the past decades. The population grew from 10.860 million to 21.516 million, the GDP per capital increased from 4,611 RMB to 99,139 RMB [36], and the built area increased from $397 \mathrm{~km}^{2}$ to $1386 \mathrm{~km}^{2}$ during the decade of 1990-2014 [37]. The fast-paced urban expansion and rising income level result in the increasing car dependence. At the end of 2014, Beijing had 5.591 million vehicles, of which $78.20 \%$ were privately owned. And $45 \%$ households had cars [36]. Car has become an important travel mode in individual 


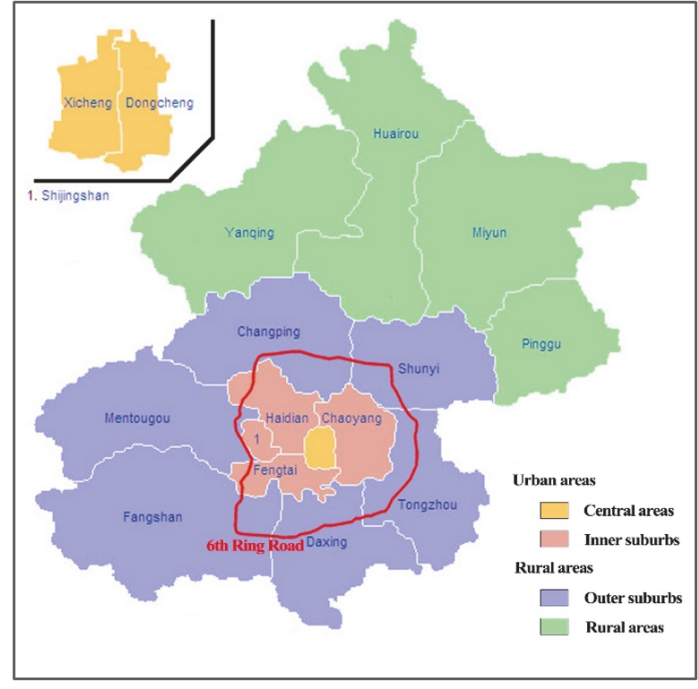

Figure 1: The study area in Beijing, China.

daily life. According to the fifth household travel survey conducted by Beijing Municipal Commission of Transport in 2014 , car trips accounted for $31.96 \%$ of all trips in Beijing.

In order to reduce car dependence and address the problems such as traffic congestion and air pollution, great importance has been attached to urban rail transit (URT). By October 2014, Beijing URT system had shaped an extensive network with 17 lines, 231 stations, and $465.4 \mathrm{~km}$ in length, since the first URT line was opened in 1981. Despite the rapid development of URT, Beijing still faced heavy traffic congestion and serious air pollution, for which the increasing car dependence is responsible.

Considering most of the URT stations were located within 6th ring road in 2014, we focus on the area within 6th ring road (about $2267 \mathrm{~km}^{2}$ ) in Beijing, as shown in Figures 1 and 2 .

\subsection{Data}

3.2.1. Tour Data. A tour is defined as a sequence of trips that starts and ends at home $[30,34]$. Tour data used in the study comes from Beijing Household Travel Survey (BHTS). This survey was conducted between July and October in 2014 by Beijing Municipal Commission of Transport. In order to develop a representative sample, 16 districts, 999 communities, and 40,003 households with 101,815 respondents were included in the survey. The surveyed households accounted for $0.60 \%$ of total households in Beijing in 2014. All respondents were interviewed face-to-face at their home and were asked about household sociodemographic information and their travel diary which includes trip purpose, origin, destination, travel mode, duration, frequency, etc.

In order to tackle the residential self-selection problem $[10,13,38]$, we consider the characteristics of different housing types in China's unique diversified housing system and focus on a subsample with exogenous residential locations. Danwei housing is provided by danwei ("Danwei is a generic term denoting the Chinese socialist workplace and the specific range of practice that is embodies" [39]) in which households have virtually no freedom to choose residential locations [40]. Thus households living in danwei housings which accounted for $16.06 \%$ of all surveyed households were selected. Only fully responding households within 6th ring road were chosen for analysis, reducing the dataset to 5676 households.

Based on the individual travel diary of the selected households, 29139 unlinked person trips were included and chained into home-based tours. A total of 12721 tours were created. A single tour may involve more than one travel mode. A tour's main mode was assigned using the following priority order: URT, bus, car, cycling, walking, and others. This priority order is for two reasons: one is that higher priority modes have higher probability of taking up the longest part of the tour; the other is that the lower priority modes can be treated as feeder modes [33]. Then, we selected the sample using the following criteria: (1) there is at least one work activity within the tour; (2) tours which travel distance less than $5 \mathrm{~km}$ are excluded, since in short-distance tours, people prefer walking and cycling rather than public transit and car. Using these criteria, 3077 home-based work tours were selected for our study. The residential locations and workplaces are shown in Figure 2.

3.2.2. Built Environment Data. With the development of location based technology, point of interests (POIs) of the electronic map have almost covered every building in the urban area. In this study, we try to build a land use dataset based on the POI information. First, all POIs within 6th ring road of Beijing were crawled from Baidu.com. After cleaning the data, there are a total of 198,608 POIs, which are classified into 17 categories and 109 subcategories according to their land use characteristics. Then, based on POI names and addresses, gross floor area data of POIs were crawled from fang.com and baidu.com. As for the POIs that were not supplemented with floor area data in the above step, the mean floor areas of POIs in the same subcategory would be taken as their floor areas. After completing POI information, neighborhood land use characteristics can be estimated based on POI types and floor areas.

We also collected street network and bus network data from Beijing Municipal Commission of Transport and beijingcitylab.com, respectively. Coupled with URT network and land use data coded by authors, a built environment database was established in the ArcGIS 10.3.

Then, in order to append each individual with built environment data, we first matched residential and workplace addresses with coordinates by which each individual was geocoded into the ArcGIS platform. Then, we defined 1 $\mathrm{km}$ buffer zone as a neighborhood at a given address and joined built environment data onto buffer zones linked to each individual. The $1 \mathrm{~km}$ buffer radius is based on about a ten-minute walking distance, approximating what can be accessed on the road network [32].

3.3. Variables. Variables used in this study include residential and workplace built environment characteristics, household, 


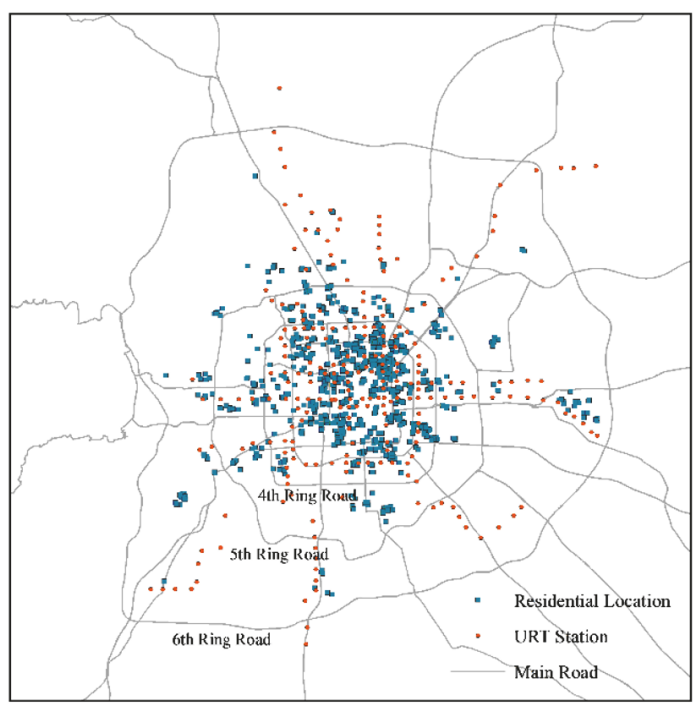

(a) Residential locations

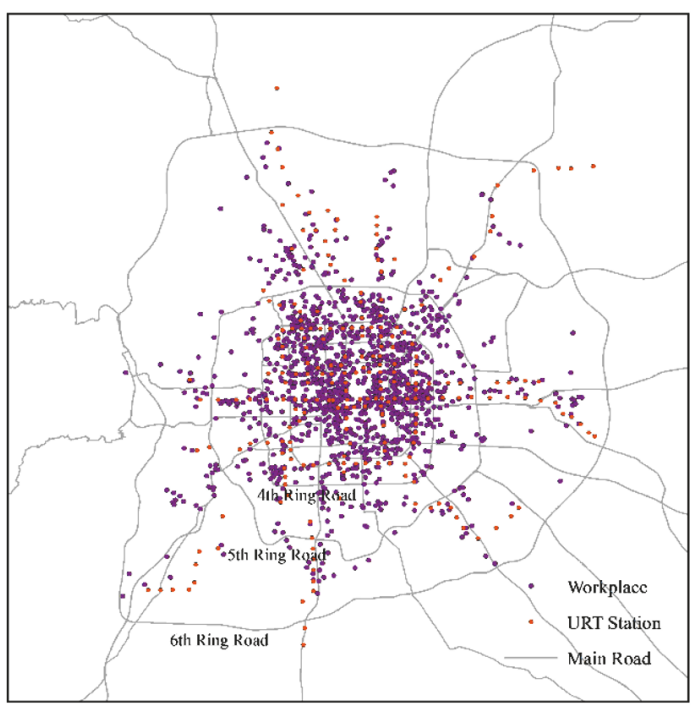

(b) Workplaces

FIgURE 2: Residential locations and workplaces in this study.

and individual characteristics and aspects of travel behavior. Table 1 presents the detail information on the variable names and definitions as well as the descriptive statistics. In order to explore the URT effect on car ownership and use, we used three dummy variables to evaluate residential and workplace proximity to URT. Since the service level of URT (e.g., transportation capacity, scheduling.) is highly related to the travel demand and the travel demand is associated with the surrounding land use, the effect of URT service level might be successfully captured by these explanatory variables (such as land use density and diversity) in our study. Therefore, we did not consider the URT service level further, which is in line with previous studies $[4,10,41,42]$.

As shown in Table 1, for the sampled households, the annual income is mainly between 50 and 150 thousand CNY, and $59.1 \%$ of them have one or more cars. There is an average of less than one child per household but more than one licensed drivers. For the sampled individuals, the average age is $39.448 .55 .8 \%$ of them are male, $58.8 \%$ have a driving license, and $29.6 \%$ choose to travel by cars. Besides, $40.2 \%$ of the sampled individuals can access the URT service both in their residential and workplace neighborhoods, and $43.9 \%$ either live or work within URT catchment areas. As for the tours, the average travel distance is $21.088 \mathrm{~km}$, and an average of 1.169 stops is included in a tour.

3.4. Model Specification. We assume that car use behavior is directly affected by sociodemographics, built environment characteristics, car ownership, and travel characteristics (e.g., travel distance). Meanwhile, car ownership and travel distance themselves are also influenced by sociodemographics and built environment, which results in the indirect effects of built environment on car use through the mediating variables car ownership and travel distance, as shown in Figure 3. Car ownership and travel distance are the endogenous variables

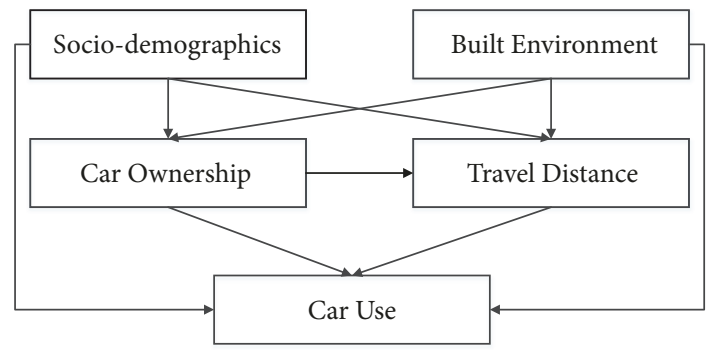

FIgURE 3: Potential relationship between built environment and travel behavior.

in some relationships and also the exogenous variables of car use behavior.

Considering the mediating effects of car ownership and travel distance simultaneously, structural equation modeling (SEM), which has been frequently used to explore the complex relationship between built environment and travel behavior $[15,34,35]$, was applied in this study. Compared to discrete choice models and multivariate regression models, SEM is more capable of handling the complex relationship among endogenous and exogenous variables and identifying the direct, indirect, and total effects [35]. An SEM for observed endogenous and exogenous variables can be defined as follows [35]:

$$
\eta=B \eta+\Gamma \xi+\zeta
$$

with $\eta=L \times 1$ matrix of endogenous variables, $\xi=K \times 1$ matrix of exogenous variables, $B=L \times L$ matrix of coefficients of the endogenous variables, $\Gamma=L \times K$ matrix of coefficients of the exogenous variables, and $\zeta=L \times 1$ matrix of residuals of endogenous variables. In this study, the endogenous and exogenous variables are all observed. 


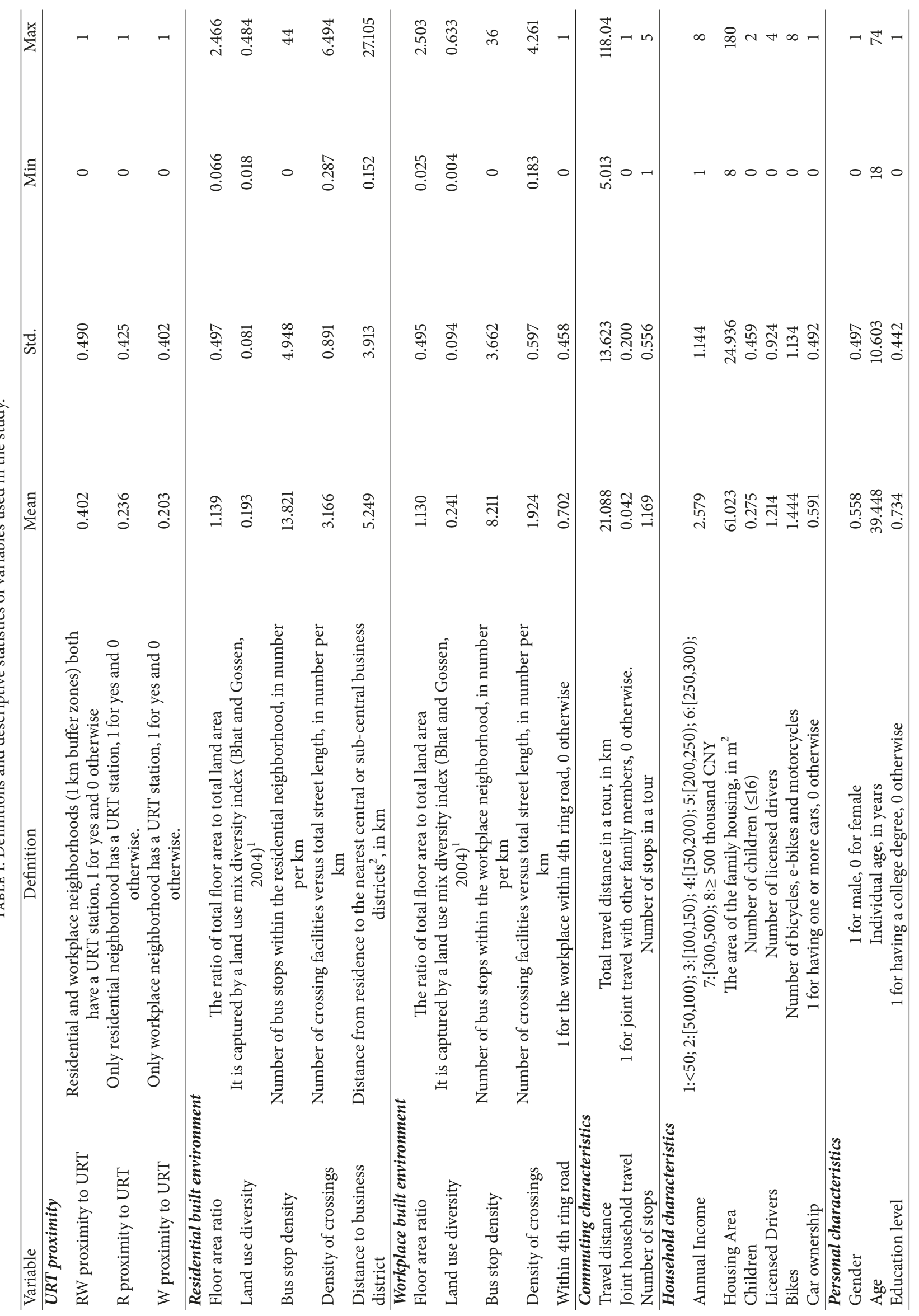




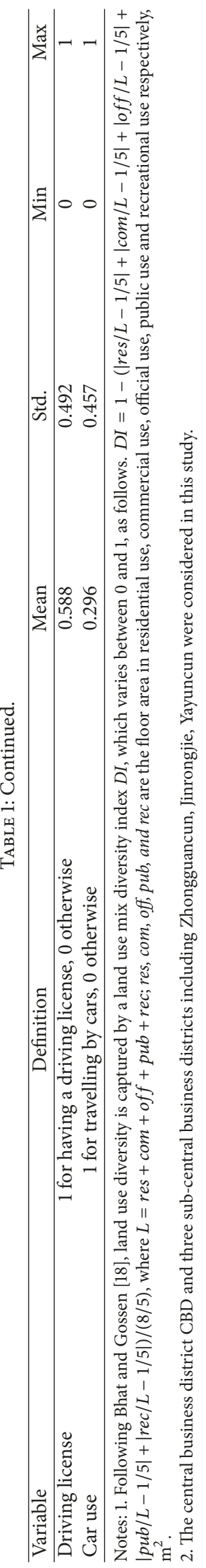


TABLE 2: Model fit indices for the car ownership and use model.

\begin{tabular}{lcc}
\hline Model fit indices & Cut-off value & Model-based value \\
\hline$\chi^{2}$ (df), $\mathrm{p}$ & $\mathrm{p}>0.05$ & $68.853(18), \mathrm{p} \leq 0.001$ \\
RMSEA (root mean square error of approximation) & $<0.05$ & 0.030 \\
WRMR (weighted root mean square residual) & $<1.00$ & 0.953 \\
CFI (comparative fit index) & $>0.90$ & 0.986 \\
TLI (Tucker-Lewis index) & $>0.90$ & 0.941 \\
\hline
\end{tabular}

As for the SEM estimation, the maximum likelihood (ML) method is generally used. But a basic assumption of the ML estimator is the multivariate normal distribution of all continuous endogenous variables [43], which is not always met in reality. Besides, the variables car ownership and car use are both categorical. So the weighted least squares mean and variance adjusted (WLSMV) estimator, which accounts for nonnormally distributed data, was applied in this study. Then, the estimation of the SEM model was conducted using the software M-plus.

\section{Results}

The SEM model was estimated using WLSMV method. The links from household and personal characteristics with no statistical significance ( $\mathrm{p}>0.1$ ) were removed, as well as the links from workplace built environment to car ownership, since the workplace built environment variables have no significantly direct effects on car ownership and no significantly indirect effects on travel distance and car use through car ownership. Then, the model was re-estimated. Table 2 presents the model fit indices and their corresponding cutoff values. The $\chi^{2}$-statistic, which compares the observed and predicted variance-covariance matrices, is highly dependent on sample size. With large sample size, it is difficult to accept the null hypothesis. In other words, this index might be meaningless to large samples. So we can ignore this index in this study for the large sample size. Other indices suggest that the model fits the data well.

The standardized direct, indirect and total effects on car ownership, travel distance and car use are shown in Table 3. In this paper, we not only focus on whether URT plays a role in car ownership and use decision, but attempt to explore whether living near a URT station influences car ownership and use differently compared with working near a URT station as well. Meanwhile, we want to know how URT influences car use considering the mediating effects of car ownership and travel distance simultaneously.

4.1. Effects on Car Ownership. After controlling sociodemographics and other built environment variables, URT still has a significant impact on car ownership, which echoes other recent studies $[10,11,16]$. Living near URT by itself is not associated with car ownership, but if the workplace is near a URT station, people are less likely to own cars. People who live and work both within URT catchment areas have lower probability of owning cars.
With respect to other residential built environment variables, lower density of crossings and longer distance to business district are associated with higher probability of owning cars. Floor area ratio and land use diversity, however, show no significant effect on car ownership.

As for sociodemographic characteristics, they play a major role in determining car ownership level, which is consistent with previous studies [7, 44]. Higher annual income, larger housing area, more children, and licensed drivers are significantly associated with higher probability of owning cars, while number of bikes has significantly negative impacts on car ownership.

4.2. Effects on Travel Distance. After controlling sociodemographics and other built environment variables, URT significantly influences travel distance. Either living near a URT station, working near a URT station, or living and working close to URT all have significant and positive effects on travel distance, while the indirect effects through the mediating variable car ownership are not significant.

As for other residential built environment variables, land use diversity has a negative impact on travel distance, while longer distance to business district is related to longer distance travelled. Contrary to the negative effects of residential bus stop density, bus stop density in workplace neighborhoods is positively associated with travel distance. This might be because people probably include more activities in a tour after work if the bus has higher accessibility at the workplaces, which may lengthen the travel distance, whereas residential neighborhoods with high bus stop density usually have high land use density and diversity, which provides more employment opportunities and might shorten commuting distance. In addition, working within 4th ring road is significantly associated with short travel distance.

In terms of commuting characteristics, a tour which is a joint travel with other family members and includes more stops is more likely to have a longer travel distance. This is in line with our expectation.

Interestingly, the effects of household characteristics on travel distance mainly produce through car ownership. Namely, travel distance seems to be influenced only indirectly by annual income, number of children, and number of licensed drivers. Higher annual income, more children, and licensed drivers are indirectly associated with longer travel distance. Thus, ignoring car ownership as a mediating variable may result in a misspecification of sociodemographic effects on travel distance. In addition, housing area and number of bikes show significantly direct impacts on travel 
TABLE 3: Standardized direct, indirect, and total effects on car ownership, travel distance, and car use.

\begin{tabular}{|c|c|c|c|c|c|c|c|}
\hline \multirow{2}{*}{ Variable } & \multirow{2}{*}{$\begin{array}{c}\text { Car ownership } \\
\text { Direct }\end{array}$} & \multicolumn{3}{|c|}{ Travel Distance } & \multicolumn{3}{|c|}{ Car use } \\
\hline & & Total & Direct & Indirect & Total & Direct & Indirect \\
\hline \multicolumn{8}{|l|}{ URT proximity } \\
\hline RW proximity to URT & $-0.082^{* *}$ & $0.064^{* *}$ & $0.069^{* *}$ & -0.005 & $-0.103^{* * *}$ & -0.036 & $-0.068^{* *}$ \\
\hline $\mathrm{R}$ proximity to URT & -0.046 & $0.105^{* * *}$ & $0.108^{* * *}$ & -0.003 & -0.005 & 0.027 & -0.032 \\
\hline W proximity to URT & $-0.056^{*}$ & $0.078^{* * *}$ & $0.081^{* * *}$ & -0.003 & $-0.045^{*}$ & -0.002 & -0.043 \\
\hline \multicolumn{8}{|l|}{ Residential built environment } \\
\hline Floor area ratio & 0.037 & -0.007 & -0.009 & 0.002 & 0.008 & -0.025 & 0.033 \\
\hline Land use diversity & 0.026 & $-0.046^{* *}$ & $-0.047^{* *}$ & 0.001 & -0.003 & -0.022 & 0.019 \\
\hline Bus stop density & 0.019 & $-0.057^{* * *}$ & $-0.058^{* * *}$ & 0.001 & 0.005 & -0.006 & 0.011 \\
\hline Density of crossings & $-0.085^{* * *}$ & 0.0002 & 0.005 & $-0.0048^{*}$ & $-0.061^{* * *}$ & 0.016 & $-0.077^{* * *}$ \\
\hline Distance to business district & $0.051^{*}$ & $0.117^{* * *}$ & $0.114^{* * *}$ & 0.003 & 0.011 & $-0.046^{*}$ & $0.057^{* *}$ \\
\hline \multicolumn{8}{|l|}{ Workplace built environment } \\
\hline Floor area ratio & -- & -0.032 & -0.032 & -- & $-0.093^{* * *}$ & $-0.090^{* * *}$ & -0.003 \\
\hline Land use diversity & -- & -0.020 & -0.020 & -- & $-0.038^{*}$ & $-0.036^{*}$ & -0.002 \\
\hline Bus stop density & -- & $0.042^{* * *}$ & $0.042^{* * *}$ & -- & 0.008 & 0.004 & $0.004^{* *}$ \\
\hline Density of crossings & -- & -0.019 & -0.019 & -- & -0.008 & -0.006 & -0.002 \\
\hline Within 4 th ring road & -- & $-0.221^{* * *}$ & $-0.221^{* * *}$ & -- & 0.022 & $0.043^{*}$ & $-0.021^{* * *}$ \\
\hline \multicolumn{8}{|l|}{ Commuting characteristics } \\
\hline Travel distance & -- & -- & -- & -- & $0.094^{* * *}$ & $0.094^{* * *}$ & -- \\
\hline Joint household travel & -- & $0.028^{*}$ & $0.028^{*}$ & -- & $0.466^{* * *}$ & $0.463^{* * *}$ & 0.003 \\
\hline Number of stops & -- & $0.049^{* * *}$ & $0.049^{* * *}$ & -- & $0.037^{*}$ & 0.032 & $0.005^{* *}$ \\
\hline \multicolumn{8}{|l|}{ Household characteristics } \\
\hline Annual Income & $0.147^{* * *}$ & $0.008^{* *}$ & -- & $0.008^{* *}$ & $0.133^{* * *}$ & -- & $0.133^{* * *}$ \\
\hline Housing area & $0.071^{* * *}$ & $0.03^{* *}$ & $0.026^{* *}$ & $0.004^{*}$ & 0.013 & $-0.054^{* *}$ & $0.067^{* * *}$ \\
\hline Children & $0.086^{* * *}$ & $0.005^{* *}$ & -- & $0.005^{* *}$ & 0.029 & $-0.049^{* *}$ & $0.078^{* * *}$ \\
\hline Licensed Drivers & $0.520^{* * *}$ & $0.029^{* *}$ & -- & $0.029^{* *}$ & $0.101^{* * *}$ & $-0.371^{* * *}$ & $0.472^{* * *}$ \\
\hline Bikes & $-0.054^{* *}$ & $-0.089^{* * *}$ & $-0.086^{* * *}$ & $-0.003^{*}$ & $-0.133^{* * *}$ & $-0.076^{* * *}$ & $-0.057^{* * *}$ \\
\hline Car ownership & -- & $0.056^{* *}$ & $0.056^{* *}$ & -- & $0.907^{* * *}$ & $0.902^{* * *}$ & $0.005^{* * *}$ \\
\hline \multicolumn{8}{|l|}{ Personal characteristics } \\
\hline Gender & -- & -- & -- & -- & $0.135^{* * *}$ & $0.135^{* * *}$ & -- \\
\hline Age & -- & $-0.040^{* *}$ & $-0.040^{* *}$ & -- & $0.054^{* *}$ & $0.058^{* *}$ & $-0.004^{*}$ \\
\hline Education level & -- & $0.049^{* *}$ & $0.049^{* *}$ & -- & $0.005^{* *}$ & -- & $0.005^{* *}$ \\
\hline Driving license & -- & -- & -- & -- & $0.235^{* * *}$ & $0.235^{* * *}$ & -- \\
\hline
\end{tabular}

Note. $*$ significant at $10 \%$ level, $* *$ significant at $5 \%$ level, and $* * *$ significant at $1 \%$ level. “--" indicates the links that are not included in the model.

distance. Owning cars contributes to long travel distance. As for personal characteristics, age has a negative effect on travel distance, and higher education level is associated with longer travel distance.

4.3. Effects on Car Use. After controlling sociodemographics and other built environment variables, URT still plays an important role in car use behavior. Living within URT catchment areas by itself has no significant effect on car use, but if the workplace is near a URT station, people have lower probability of using cars. People who both live and work near URT are less likely to travel by car. This is in line with the finding of Kwoka et al. [45]. Moreover, the URT effects on car use seem to mainly produce through the mediating variable car ownership. The indirect effects of RW proximity to URT, $\mathrm{R}$ proximity to URT, and $\mathrm{W}$ proximity to URT through car ownership are $-0.074,-0.042$, and -0.050 , while these indirect effects through travel distance are 0.006, 0.010, and 0.008, respectively. So the mediating impact of car ownership is greater than travel distance. If we only focus on the direct effects of URT, we may get a misspecification of URT effects on car use.

It is noteworthy that car use is mainly affected by residential built environment characteristics indirectly, while it is mainly influenced by workplace built environment factors directly. Density of crossing in residential neighborhood has a negative effect on car use. In addition, higher floor area ratio and higher land use diversity at the workplace are significantly associated with lower probability of using car, while the residential land use density and diversity show no significant impact on car use. Namely, land use characteristics at the workplace are more influential on mode choice than at the residence, which is consistent with the previous studies $[2,31]$. 
For the commuting characteristics, longer travel distance increases the probability of using car. A tour which is a joint travel with other family members is more likely to travel by car, and number of stops in a tour is positively associated with car use. This is consistent with the previous studies $[31,33,34]$.

With regard to household characteristic variables, the signs of some variables' direct and indirect effects are opposite. So the combination of the direct and indirect effects determines the total effects. We found that the indirect effects of household characteristics seem to play a more important role in determining the total effects. Annual income, number of licensed drivers, and owning cars have significantly positive effects on car use, while number of bikes is negatively related to car use. Interestingly, the annual income effect on car use seems to exist only through car ownership, which is consistent with the finding of Van Acker and Witlox [35]. As for personal characteristic variables, people who are male and older are more likely to use cars. Besides, having a driving license or having a higher level of education can increase the probability of travelling by cars.

\section{Discussion}

Previous studies mainly focus on the effects of residential proximity to URT on car ownership and use $[1,10,11$, 16], while we not only explore whether living within URT catchment areas affects car ownership and use differently from working near a URT station but also investigate how URT influences car use through the mediating variables car ownership and travel distance as well in this study.

After controlling for sociodemographics and other built environment factors, we find that URT plays a role in reducing car ownership level, which echoes other recent studies $[10,11,16]$. In these studies, URT proximity is all treated as a dummy variable. If there is a URT station within a certain distance (e.g., $500 \mathrm{~m}, 800 \mathrm{~m}$, and $1 \mathrm{~km}$ ), the value of the dummy variable is 1 and 0 otherwise. In contrast, $\mathrm{Li}$ and Zhao [1] and Shen et al. [4] used the distance to the closest URT station to evaluate URT proximity and found no significant effect on car ownership. So the quantification of URT proximity influences the results to a great degree. The URT effect on car ownership may occur within a simple threshold.

We also find that URT has a significant and negative impact on car use, which is in line with the previous studies $[4,16,17]$. Further, the URT effects on car use seem to mainly produce through the mediating variable car ownership, and the mediating effect of travel distance is relatively small. To our knowledge, very few studies have explored the URT influence on travel behavior considering the intermediary nature of car ownership and travel distance simultaneously. Our study fills this gap and identifies the mediating role of car ownership and travel distance.

Moreover, different from the previous studies that focus on the effect of residential proximity to URT $[1,10,11,16]$, we use three dummy variables to indicate residential and workplace proximity to URT and examine their effects on travel behavior. It is found that living within URT catchment areas by itself does not influence car ownership and use significantly, but if working near URT station areas, people have lower probability of owning and using cars. People with residences and workplaces both near URT are less likely to own and use cars. To our knowledge, only Kwoka et al. [45] explored whether working near a URT station affects travel behaviors of workers differently than living near a URT station. But they only demonstrated the travel behavior differences from the aggregate level using simple statistical analysis. By contrast, we control sociodemographics and other built environment factors and examine the relationship between residential and workplace proximity to URT and travel behavior based on disaggregate data, which better explains the differences in travel behavior.

Admittedly, we fail to explore the causal relationship between built environment and car ownership and use based on a cross-sectional sample. More advanced modeling techniques or longitudinal data will be considered in further study. In addition, due to data availability, travel-related attitudes or subjective perceptions of built environment attributes are not taken into account. Some studies used attitude and perception variables to address the residential self-selection problem, while we focus a subsample with exogenous residential locations, which can also tackle this problem.

\section{Conclusion}

This paper explored the URT effects on car ownership and use considering the intermediary nature of car ownership and travel distance simultaneously. We took advantage of the unique diversified housing system in China,and selected a subsample with exogenous residential locations to address the residential self-selection issue. Based on 3077 homebased work tour data, we developed a SEM model to investigate the complex relationship among URT, car ownership, travel distance, and car use. The results indicate that URT has important effects on car ownership and use. Living within URT catchment areas by itself is not significantly associated with car ownership and use, but if the workplace is near a URT station, people are less likely to own and use cars. People who both live and work near URT have lower probability of owning and using cars. Moreover, the URT effect on car use seems to mainly produce through the mediating variable car ownership, and the mediating impact of travel distance is relatively small. If we only focus on the direct effects of URT, we may get a misspecification of URT effects on car use.

As for the influence of other built environment variables, residential land use density (FAR) and diversity seem more influential on car ownership than those at the workplaces, while they play a less important role in mode choice behavior. Besides, lower density of crossings at the residences is associated with lower probability of owning cars and using cars. Bus stop density at the residential and workplace neighborhoods show no significant effect on car ownership and use. With respect to the commuting characteristics, a tour which is a joint travel with other family members and includes more stops has higher probability of using cars, and travel distance 
is positively associated with car use. For sociodemographics, the annual income effect on car use seems to exist only through car ownership.

Our findings verify that URT-supported urban growth can be an effective strategy to discourage people from owning and using cars, which have important implications for transportation and land use planning in response to the motorization and urbanization in Beijing and in other large developing cities.

\section{Data Availability}

The data used to support the findings of this study were provided by Beijing Municipal Commission of Transport under license. Access to these data will be considered by the corresponding author upon request, with permission of Beijing Municipal Commission of Transport.

\section{Conflicts of Interest}

The authors declare that they have no conflicts of interest.

\section{Acknowledgments}

This research is supported by the Fundamental Research Funds for the Central Universities (no. 2017YJS116) and Beijing Natural Science Foundation (no. 8171003).

\section{References}

[1] S. Li and P. Zhao, "Exploring car ownership and car use in neighborhoods near metro stations in Beijing: Does the neighborhood built environment matter?" Transportation Research Part D: Transport and Environment, vol. 56, pp. 1-17, 2017.

[2] A. Soltani, "Social and urban form determinants of vehicle ownership; evidence from a developing country," Transportation Research Part A: Policy and Practice, vol. 96, pp. 90-100, 2017.

[3] R. Cervero and J. Day, "Suburbanization and transit-oriented development in China," Transport Policy, vol. 15, no. 5, pp. 315323, 2008.

[4] Q. Shen, P. Chen, and H. Pan, "Factors affecting car ownership and mode choice in rail transit-supported suburbs of a large Chinese city," Transportation Research Part A: Policy and Practice, vol. 94, pp. 31-44, 2016.

[5] X. Huang, X. J. Cao, X. Cao, and J. Yin, "How does the propensity of living near rail transit moderate the influence of rail transit on transit trip frequency in Xian?" Journal of Transport Geography, vol. 54, pp. 194-204, 2016.

[6] Urban rail transit in India, wikipedia, 2018.

[7] Y. Jiang, P. Gu, Y. Chen, D. He, and Q. Mao, "Influence of land use and street characteristics on car ownership and use: Evidence from Jinan, China," Transportation Research Part D: Transport and Environment, vol. 52, pp. 518-534, 2017.

[8] G. Giuliano and J. Dargay, "Car ownership, travel and land use: A comparison of the US and Great Britain," Transportation Research Part A: Policy and Practice, vol. 40, no. 2, pp. 106-124, 2006.

[9] P. Anastasopoulos, M. Karlaftis, J. Haddock, and F. Mannering, "Household automobile and motorcycle ownership analyzed with random parameters bivariate ordered probit model," Transportation Research Record, no. 2279, pp. 12-20, 2012.

[10] Y. Zhang, S. Zheng, C. Sun, and R. Wang, "Does subway proximity discourage automobility? Evidence from Beijing," Transportation Research Part D: Transport and Environment, vol. 52, pp. 506-517, 2017.

[11] X. Huang, X. Cao, J. Yin, and X. Cao, "Effects of metro transit on the ownership of mobility instruments in Xian, China," Transportation Research Part D: Transport and Environment, vol. 52, pp. 495-505, 2017.

[12] X. Huang, X. (Jason) Cao, J. Yin, and X. Cao, "Can metro transit reduce driving? Evidence from Xian, China," Transport Policy, 2018.

[13] C. R. Bhat and J. Y. Guo, "A comprehensive analysis of built environment characteristics on household residential choice and auto ownership levels," Transportation Research Part B: Methodological, vol. 41, no. 5, pp. 506-526, 2007.

[14] J. Cao and X. Cao, "The Impacts of LRT, Neighbourhood Characteristics, and Self-selection on Auto Ownership: Evidence from Minneapolis-St. Paul," Urban Studies, vol. 51, no. 10, pp. 2068-2087, 2014.

[15] C. Ding, D. Wang, C. Liu, Y. Zhang, and J. Yang, "Exploring the influence of built environment on travel mode choice considering the mediating effects of car ownership and travel distance," Transportation Research Part A: Policy and Practice, vol. 100, pp. 65-80, 2017.

[16] C. Zegras, "The built environment and motor vehicle ownership and use: Evidence from Santiago de Chile," Urban Studies, vol. 47, no. 8, pp. 1793-1817, 2010.

[17] H. Pan, Q. Shen, and T. Zhao, "Travel and car ownership of residents near new suburban metro stations in Shanghai, China," Transportation Research Record, no. 2394, pp. 63-69, 2013.

[18] C. R. Bhat and R. Gossen, "A mixed multinomial logit model analysis of weekend recreational episode type choice," Transportation Research Part B: Methodological, vol. 38, no. 9, pp. 767787, 2004.

[19] A. Soltani and A. Shams, "Analyzing the influence of neighborhood development pattern on modal choice," Journal of Advanced Transportation, vol. 2017, 2017.

[20] M. Boarnet and R. Crane, "The influence of land use on travel behavior: Specification and estimation strategies," Transportation Research Part A: Policy and Practice, vol. 35, no. 9, pp. 823845, 2001.

[21] S. Handy, X. Cao, and P. Mokhtarian, "Correlation or causality between the built environment and travel behavior? Evidence from Northern California," Transportation Research Part D: Transport and Environment, vol. 10, no. 6, pp. 427-444, 2005.

[22] M. Yazdanpanah and M. Hadji Hosseinlou, "The impact of perception toward the built environment in airport access mode choice using hybrid choice modeling," Journal of Advanced Transportation, vol. 2017, 13 pages, 2017.

[23] J. Hong, Q. Shen, and L. Zhang, "How do built-environment factors affect travel behavior? A spatial analysis at different geographic scales," Transportation, vol. 41, no. 3, pp. 419-440, 2014.

[24] S. Handy, "Methodologies for exploring the link between urban form and travel behavior," Transportation Research Part D: Transport and Environment, vol. 1, no. 2, pp. 151-165, 1996.

[25] R. Ewing and R. Cervero, "Travel and the built environment: a meta-analysis," Journal of the American Planning Association, vol. 76, no. 3, pp. 265-294, 2010. 
[26] N. Limtanakool, M. Dijst, and T. Schwanen, "The influence of socioeconomic characteristics, land use and travel time considerations on mode choice for medium- and longer-distance trips," Journal of Transport Geography, vol. 14, no. 5, pp. 327-341, 2006.

[27] P. Zhao, "The Impact of the Built Environment on Individual Workers' Commuting Behavior in Beijing," International Journal of Sustainable Transportation, vol. 7, no. 5, pp. 389-415, 2013.

[28] Y. Shiftan and Y. Barlach, "Effect of employment site characteristics on commute mode choice," Transportation Research Record, no. 1781, pp. 19-25, 2002.

[29] R. Cervero, "Built environments and mode choice. Toward a normative framework," Transportation Research Part D: Transport and Environment, vol. 7, no. 4, pp. 265-284, 2002.

[30] C. Chen, H. Gong, and R. Paaswell, "Role of the built environment on mode choice decisions: additional evidence on the impact of density," Transportation, vol. 35, no. 3, pp. 285-299, 2008.

[31] C. Ding, Y. Lin, and C. Liu, "Exploring the influence of built environment on tour-based commuter mode choice: a cross-classified multilevel modeling approach," Transportation Research Part D: Transport and Environment, vol. 32, pp. 230238, 2014.

[32] L. Frank, M. Bradley, S. Kavage, J. Chapman, and T. K. Lawton, "Urban form, travel time, and cost relationships with tour complexity and mode choice," Transportation, vol. 35, no. 1, pp. 37-54, 2008.

[33] C. Q. Ho and C. Mulley, "Multiple purposes at single destination: a key to a better understanding of the relationship between tour complexity and mode choice," Transportation Research Part A: Policy and Practice, vol. 49, pp. 206-219, 2013.

[34] V. van Acker and F. Witlox, "Commuting trips within tours: How is commuting related to land use?" Transportation, vol. 38, no. 3, pp. 465-486, 2011.

[35] V. Van Acker and F. Witlox, "Car ownership as a mediating variable in car travel behaviour research using a structural equation modelling approach to identify its dual relationship," Journal of Transport Geography, vol. 18, no. 1, pp. 65-74, 2010.

[36] Q. Jia, Beijing Statistical Yearbook, China, China Statistical Press, Beijing, China, 2015.

[37] X. Chen, China City Statistical Yearbook, China Statistical Press, Beijing, 2015.

[38] P. L. Mokhtarian and X. Cao, "Examining the impacts of residential self-selection on travel behavior: a focus on methodologies," Transportation Research Part B: Methodological, vol. 42, no. 3, pp. 204-228, 2008.

[39] D. Bray, Social space and governance in urban China: The danwei system from origins to reform, Stanford University Press, 2005.

[40] D. Wang and T. Lin, "Residential self-selection, built environment, and travel behavior in the chinese context," Journal of Transport and Land Use, vol. 7, no. 3, pp. 5-14, 2014.

[41] R. Cervero and M. Duncan, "Residential self-selection and rail commuting: a nested logit analysis," Working paper, University of California, Berkeley, 2002.

[42] D. Houston, M. G. Boarnet, G. Ferguson, and S. Spears, "Can compact rail transit corridors transform the automobile city? Planning for more sustainable travel in Los Angeles," Urban Studies, vol. 52, no. 5, pp. 938-959, 2015.

[43] R. B. Kline, Principles and Practice of Structural Equation Modeling, Guilford Press, New York, NY, USA, 2005.
[44] C. R. Bhat and V. Pulugurta, "A comparison of two alternative behavioral choice mechanisms for household auto ownership decisions," Transportation Research Part B: Methodological, vol. 32, no. 1, pp. 61-75, 1998.

[45] G. J. Kwoka, E. E. Boschmann, and A. R. Goetz, "The impact of transit station areas on the travel behaviors of workers in Denver, Colorado," Transportation Research Part A: Policy and Practice, vol. 80, pp. 277-287, 2015. 


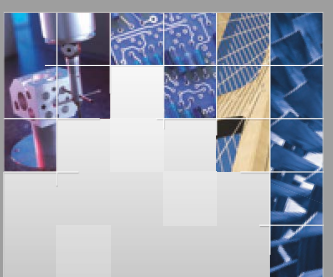

\section{Enfincering}
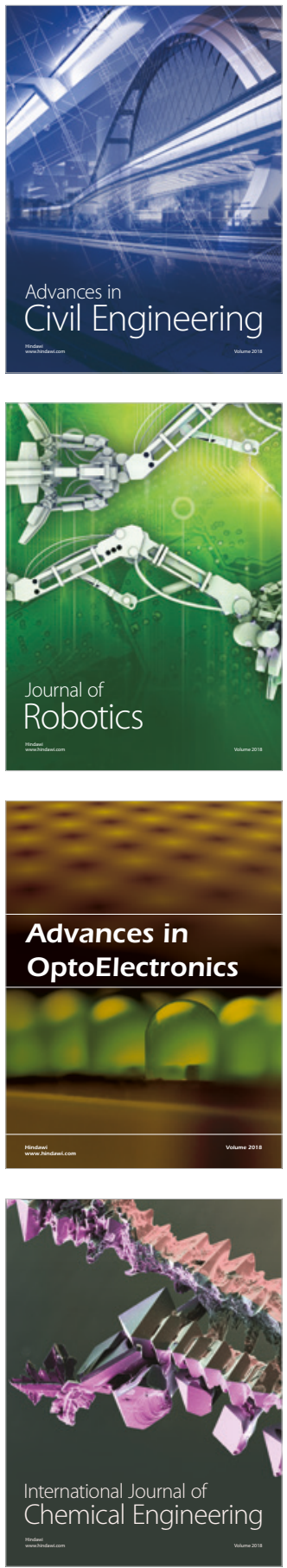

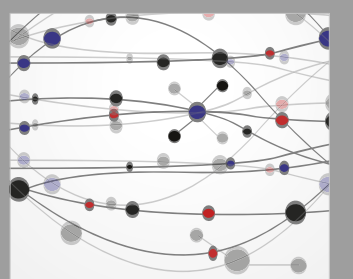

\section{Rotating \\ Machinery}

The Scientific World Journal

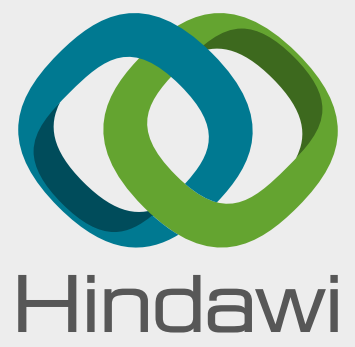

Submit your manuscripts at

www.hindawi.com
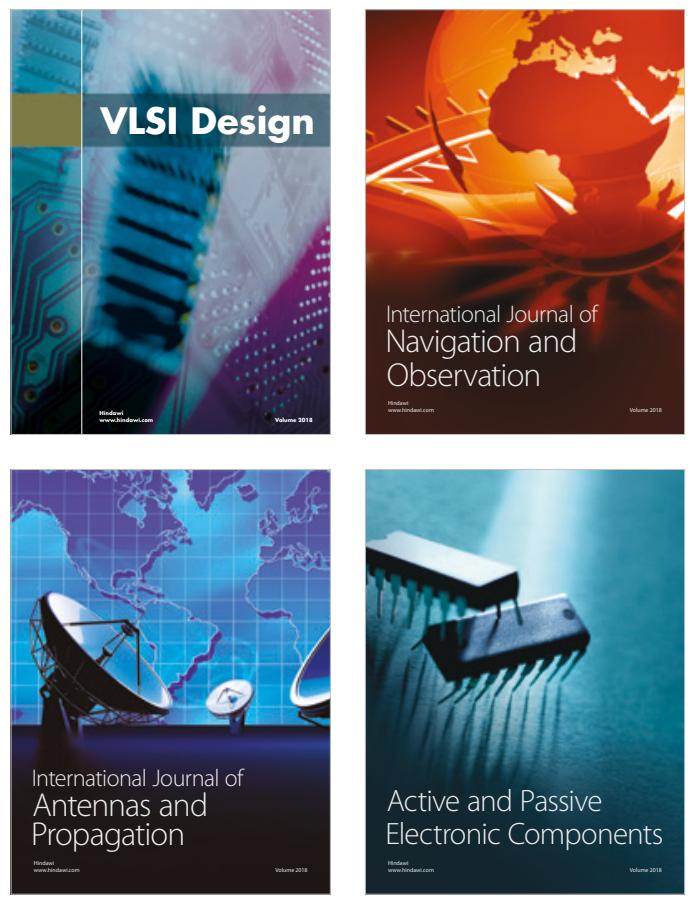
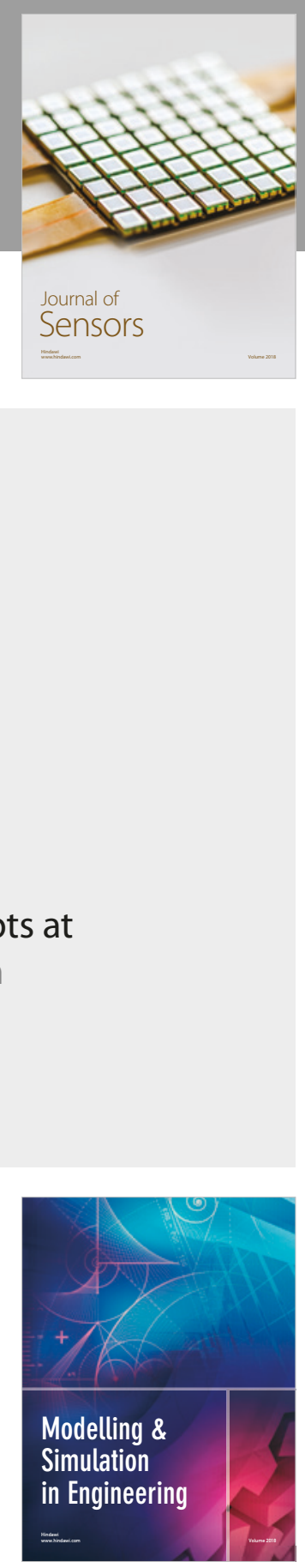

\section{Advances \\ Multimedia}
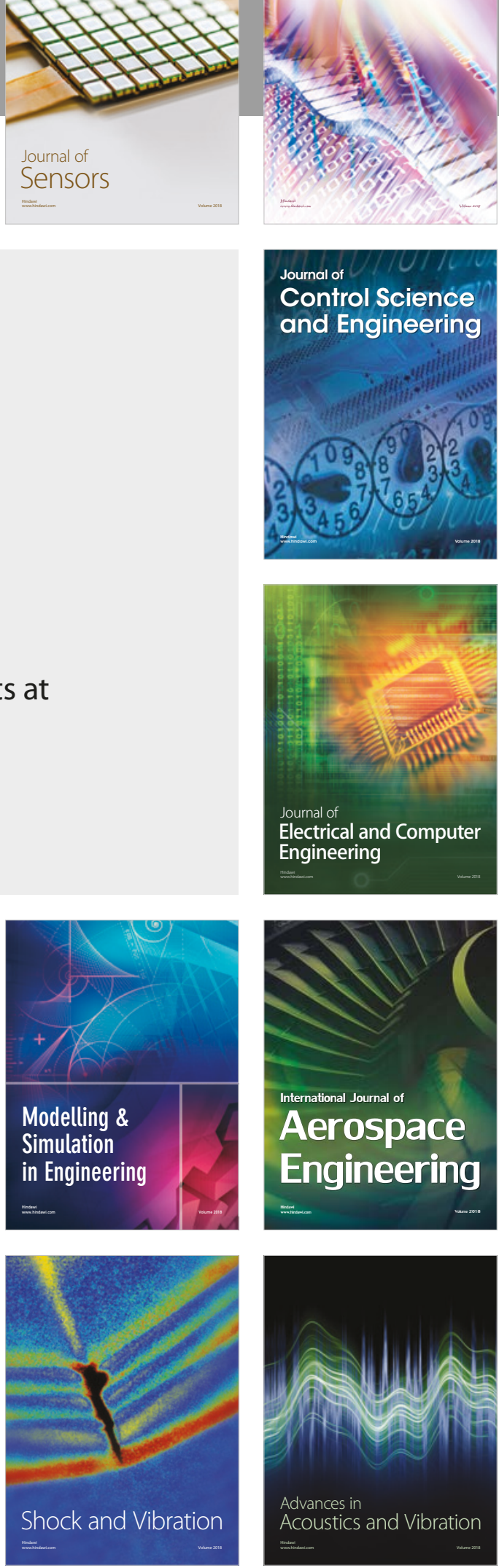